\title{
Comparing the efficacy of two-week therapy with bismuth quadruple versus levofloxacin concomitant regimen for Helicobacter Pylori infection in Syrian patients. A randomized controlled trial.
}

Marouf Muhammad Alhalabi ( $\nabla$ e.marouf@hotmail.com )

Damascus Hospital https://orcid.org/0000-0001-5027-2096

Mohammed Waleed Alassi

Damascus Hospital

Kamal Alaa Eddin

Damascus Hospital

Khaled Cheha

Damascus Hospital

\section{Research Article}

Keywords: Helicobacter Pylori, doxycycline, tinidazole, bismuth, quadruple regimen, levofloxacin, Syria

Posted Date: February 12th, 2021

DOI: https://doi.org/10.21203/rs.3.rs-80097/v3

License: (c) (i) This work is licensed under a Creative Commons Attribution 4.0 International License. Read Full License 


\section{Abstract}

Background: Antibiotic-resistant reduces the efficacy of conventional triple therapy for Helicobacter Pylori infections worldwide, lead to varying treatment protocols according to locations. The primary outcome of this research is to estimate the eradication rates of modified bismuth quadruple versus modified levofloxacin concomitant as empirical first-line treatment by intention to treat analysis (ITT) and per-protocol analysis (PPA) in a referral hospital in Syria.

Settings and Design: an open-label parallel blind randomized controlled trial.

Methods: We randomly assigned seventy-eight naïve who tested positive for Helicobacter Pylori gastric infection, with a 1:1 ratio to (B-group) which receive (bismuth subsalicylate $524 \mathrm{mg}$ four times daily, doxycycline $100 \mathrm{mg}$, tinidazole $500 \mathrm{mg}$, and esomeprazole $20 \mathrm{mg}$, each twice per day for two weeks), or (L-group) which receive (levofloxacin $500 \mathrm{mg}$ daily, tinidazole $500 \mathrm{mg}$, amoxicillin $1000 \mathrm{mg}$, and esomeprazole $20 \mathrm{mg}$ each twice per day for two weeks). We confirmed Helicobacter Pylori eradication by stool antigen test at eight weeks.

Results: Thirty-nine patients were allocated in each group. In the B- group, thirty-eight patients completed the followup, thirty patients were cured. While in the L-group, thirty-nine completed the follow-up, thirty-two patients were cured. According to ITT, the eradication rates were $76.92 \%$, and $82.05 \%$, for the B-group and L-group respectively. Odds ratio with $95 \%$ confidence interval was 1.371 [0.454-4.146]. According to PPA, the eradication rates were $78.9 \%$, and $82.1 \%$ for the B-group and L-groups respectively. The odds ratio with $95 \%$ confidence interval was 1.219 [0.3943.774]. We didn't report serious adverse effects.

\section{Conclusions:}

The eradication rates in both therapy regimes were fair. Further trials are intended to help select the right first-line treatment for Helicobacter-Pylori Infection in the Syrian population.

Trial registration: We register this study as a standard randomized clinical trial (Clinicaltrial.gov, identifier-NCT04348786, date:29-January-2020, https://clinicaltrials.gov/ct2/show/NCT04348786).

\section{Background}

Eastern Mediterranean region countries have a high prevalence rate of Helicobacter Pylori (H.Pylori) infection [1]. Chronic infection of $\mathrm{H}$. Pylori contributes to multiple diseases such as peptic ulcer disease and subsequent bleeding [2-4], dyspepsia, gastric adenocarcinoma, [5] mucosa-associated lymphoid tissue (MALT) lymphoma [6], idiopathic thrombocytopenic purpura, [7] unexplained iron deficiency anaemia. [8] World health organization has listed the H.Pylori infection as a class 1 carcinogen.[9] Eradication of H.Pylori cures the previous diseases and can decrease the risk of gastric cancer.[10] Globally rate of eradication of $\mathrm{H}$. Pylori infection is decreasing due to increased antibiotic resistance particularly clarithromycin and levofloxacin. [11]. In eastern Mediterranean area the resistance to clarithromycin, metronidazole, levofloxacin, amoxicillin, and tetracycline were $29 \%, 61 \%, 23 \%, 14 \%, 10 \%$ respectively. [12] Several researchers reviewed many therapy regimens including sequential, concomitant, and hybrid to find the best treatment protocol. [13] The results of conventional triple therapy in Syria were disappointed, [14] Tetracycline is unavailable in Syria, we use doxycycline in bismuth quadruple regimen.[15,16] We used tinidazole instead of metronidazole in both regimens, as $\mathrm{H}$. pylori had high metronidazole resistant rate. [17] metronidazole is a very commonly used drug in Syria to treat gynaecological and gastrointestinal complaining. we didn't perform a susceptibility test of $\mathrm{H}$. Pylori to antibiotics, since it is not accessible in Syria or neighbouring countries. There is a lack of data about the efficacy of modified bismuth quadruple regimen and modified levofloxacin-containing 
quadruple concomitant regimens in Syrian patients, we conducted this trial to evaluate the efficacy and report the eradication rate according to intention to treat analysis (ITT) and per-protocol analysis (PPA).

\section{Methods}

This was an open-label parallel randomized study performed in the department of gastroenterology at the referral hospital in Damascus, Syria.

We recruited appropriate candidates from patients who visited our clinic for evaluation of dyspeptic symptoms by upper gastrointestinal endoscopy between February 2020 to August 2020. Exclusion criteria were (1) younger than 18 years and older than 80 years; (2) prior eradication treatment for $\mathrm{H}$ pylori; (3) documented reactions to any of the studied medications;(4) recent use of antibiotics, bismuth, or proton pump inhibitors (PPIs) in the preceding month; (5) pregnant or lactating women; (6) previous gastric surgery; (7) alcohol or opioid abuse; or (8) severe concurrent medical illnesses, such as liver failure, renal failure, or terminal malignancy.

All patients have undergone upper gastrointestinal endoscopy. Endoscopists have taken five gastric biopsies, two from the antrum, two from the body, and one from the incisura according to the Sydney system.[18] Pathologists confirm H. Pylori infection by microscopic examination after using haematoxylin, eosin, and Giemsa stains.[19] We sent all biopsies to the central pathology laboratory of the same referral hospital. Eligible patients were randomized in a 1:1 ratio to receive two weeks of treatment of either modified bismuth quadruple B-group or modified concomitant levofloxacin L-group. The B-group obtained bismuth subsalicylate $524 \mathrm{mg}$ q.i.d, doxycycline $100 \mathrm{mg}$, tinidazole $500 \mathrm{mg}$, esomeprazole $20 \mathrm{mg}$ each b.i.d for 14 days. While The L-group obtained levofloxacin $500 \mathrm{mg}$ q.d, tinidazole 500 mg, amoxicillin 1000 mg, and esomeprazole 20 mg each b.i.d for 14 days. We used Microsoft Excel function called (RANDBETWEEN) to generate a sequence of two randomized numbers, number one refer to the Bgroup, and number two refers to the L-group. We print each code on separate paper and insert it into sealed opaque envelopes in unchanged order, and hold it in a secure locker belonging to an independent medical staff member. After obtaining informed consent, the independent medical staff member took the top envelope in order to assign the patient to the treatment regimen. We provide written instruction to all patients on how to take the medications. We evaluated compliance by counting the number of unused medications, and considered that the patient had a good complaint if he/she had taken at least $90 \%$ of the assigned treatment protocol. The indication of treatment relied on the American College of gastroenterology guideline and Maastricht V/Florence consensus report [13,15]. Including peptic ulcer, chronic gastritis, primary gastric MALT Iymphoma, intestinal metaplasia, dyspepsia, and unexplained iron deficiency anaemia.

At the end of the treatment course, patients revisited the clinic to investigate side effects and evaluate compliance. We reported side effects such as nausea, vomiting, diarrhoea, melena, dysgeusia, and anorexia. After eight weeks, all patients visited the central laboratory of our hospital and performed stool antigen tests by using the enzyme immunoassay method (EIA).[20] Medical laboratory workers were blinded to the treatment arm. a qualified physician collected the data in a questionnaire including (1) participants' demographics; (2) smoking history; (3) medication history; (4) adverse events, and (5) results of stool antigen test. Numerical data were shown as mean, and qualitative data were expressed as a ratio.

Authors report the results of this research according to the CONSORT.

Outcomes:

Page $3 / 10$ 
The primary outcome was the $\mathrm{H}$ pylori eradication rates of the initially assigned treatment according to intention to treat analysis (ITT), and per-protocol analysis (PPA).

Sample size and statistical analysis:

Federico et al. Found that the eradication rate based on ITT was $0.92 \%$ in modified concomitant levofloxacincontaining therapy.[21] We used tinidazole instead of metronidazole in the doxycycline-bismuth regimen for the first time, So we assumed that the eradication rate was 0.5 which give us the largest sample size. [22,23] We used a power of $95 \%$, two tails test and $95 \%$ confidence level with 1:1 allocation ratio. Each treatment arm requires thirtytwo patients. We take advantage of epitools epidemiological calculators.[24] We added seven patients to each group to compensate for the predicted dropout.[25] Thirty-nine patients were allocated in each group

Statistical tests to estimate the potential differences in outcomes between the two groups were chi-square test ( $\chi 2$ test) for categorical variables, and t-test for continuous data. We reported the odds ratio with a $95 \%$ confidence interval. A P-value of less than 0.05 was considered statistically significant. We performed statistical analyses using SPSS (IBM Corp. Released in 2017. IBM SPSS Statistics for Windows, Version 25.0. Armonk, NY: IBM Corp).

\section{Results}

We collected 226 patients diagnosed with $\mathrm{H}$. pylori infection biopsy-confirmed. Seventy-eight treatment-naive patients enrolled in this study (39 patients for each group), only one B-group patient didn't complete the follow-up. [Figure 1 and Table 1] summarizes the flow chart and baseline characteristics of the patients. The gender, mean age and pharmacological side effects were similar among treatment groups, except for melena, which occurred more frequently in the B-group.

H. Pylori infection was eradicated in thirty patients from the B-group, and thirty-two patients from the L-group. The eradication rates according to ITT and PPA analysis are summarised in table (2). We didn't report serious adverse effects.

Table 1:Baseline characteristics of patients

\begin{tabular}{|c|c|c|c|}
\hline \multicolumn{3}{|c|}{ Table 1: Baseline characteristics of patients } \\
\hline & $\begin{array}{c}\text { Bismuth subsalicylate and } \\
\text { doxycycline }\end{array}$ & $\begin{array}{c}\text { levofloxacin and } \\
\text { tinidazole }\end{array}$ & P-value \\
\hline Gender & $21(55.3 \%)$ & $20(51.3 \%)$ & 0.821 \\
\hline Male & $17(44.7 \%)$ & $19(48.7 \%)$ & 0.223 \\
\hline Female & $41.82 \pm 11.914$ & $45.62 \pm 17.994$ & 1.00 \\
\hline $\begin{array}{c}\text { Age (mean years } \\
\pm \text { SD) }\end{array}$ & $16(42.1 \%)$ & $16(41 \%)$ & 0.240 \\
\hline Smoking & $2(5.3 \%)$ & $0(2.5 \%)$ & 0.160 \\
\hline Alcoholic & Adverse events & $11(28.2 \%)$ & 0.160 \\
\hline Anorexia & $5(13.2 \%)$ & $5(12.8 \%)$ & 0.347 \\
\hline Nausea & $10(26.3 \%)$ & $4(10.3 \%)$ & 0.421 \\
\hline Vomiting & $7(18.4 \%)$ & $11(28.2 \%)$ & $\leq$ \\
\hline Dysgeusia & $7(18.4 \%)$ & $0(0 \%)$ & 0.0001 \\
\hline Melena & $11(28.9 \%)$ & $0(0 \%)$ & 0.494 \\
\hline Discoloured Tongue & $1(2.6 \%)$ & $3(7.7 \%)$ & 0.310 \\
\hline Diarrhea & $6(15.8 \%)$ & & \\
\hline
\end{tabular}

Table 2: Helicobacter pylori eradication rate in therapy in modified levofloxacin concomitant and modified bismuth quadruple therapy groups 


\begin{tabular}{|c|c|c|c|c|}
\hline & $\begin{array}{c}\text { Modified levofloxacin } \\
\text { concomitant }\end{array}$ & $\begin{array}{c}\text { Modified bismuth } \\
\text { quadruple }\end{array}$ & $\begin{array}{c}\text { Odds Ratio }(95 \% \\
\text { CI) }\end{array}$ & $\begin{array}{c}\text { P- } \\
\text { Value }\end{array}$ \\
\hline ITT & $82.1 \%$ & $76.9 \%$ & $1.371(0.454,4.146)$ & 0.78 \\
\hline PPA & $82.1 \%$ & $78.9 \%$ & $1.219(0.394,3.774)$ & 0.78 \\
\hline \multicolumn{2}{|l|}{ CI=confidence interval, ITT =intention to treat analysis , PPA=per-protocol analysis } \\
\hline
\end{tabular}

\section{Discussion}

Researchers globally observed a decline in the rate of $\mathrm{H}$ pylori eradication following standard triple therapies, thus requiring a search for new therapeutic approaches. [45-48] This randomized clinical trial included 78 patients from an area of high prevalence $(\mathbb{\nabla 1 5 \%})$ of clarithromycin and levofloxacin resistant $\mathrm{H}$ pylori strains. $[1,12,14,26,27]$ Both concomitant and bismuth-containing quadruple therapies are recommended as alternative first-line treatment according to the previously mentioned guidelines, particularly in regions with a high prevalence of clarithromycin resistance.[13,15]

Our results showed that both regimens had a fair eradicating rate of $\mathrm{H}$ pylori. The eradication rate for modified levofloxacin concomitant protocol was $82.05 \%$ according to ITT analysis. While Bismuth quadruple therapy had a PPA eradication rate of $78.94 \%$, and $76.92 \%$ according to ITT analysis. The overall eradication rate of concomitant was about $3 \%$ higher than bismuth quadruple therapy but the difference didn't reach statistical significance. The result of modified levofloxacin containing therapy can be regarded as Grade D standard, while the result of bismuthcontaining therapy can be regarded as Grade $\mathrm{F}$ as proposed recently.[28] Our results are agreeing with a Metaanalysis by Essa et al. and similar research by Federico et al. in concomitant therapy both studies show that concomitant therapy is effective in the eradication of H.Pylori.[21,29] While Meta-analysis by Niv et al. found that doxycycline had good efficacy in treatment H.Pylori infection.[16] Even though this research treated patients for a longer period, [30] Our results didn't show the effectiveness mentioned in previous studies. we could explain these results by $\mathrm{H}$. Pylori resistance in CagA-homB+ strains.,[31] when health care providers are overusing the antibioticsespecially macrolides and fluoroquinolones-for treating respiratory, urinary and gynaecological infections, [32-34] outpatients incompliance to antibiotic regimen [35,35-37] and using locally produced drugs. [38,39]

Our study has a few limitations. The only method to investigate past medication was to interrogate patients. Because the absence of electronic medical records for patients, therefore, authors define "naïve" that health care providers didn't previously treat the patient for $\mathrm{H}$. Pylori infection. We depended on patients to evaluate the compliance. And we didn't perform a susceptibility test of $\mathrm{H}$. Pylori to antibiotics, because it's absent in Syria.

Our results showed that both regimens had an acceptable rate of eradication, and the difference didn't reach statistical significance. These results were highly promising in treating $\mathrm{H}$. Pylori infection in Syria.

\section{Conclusion}

The success rate of the standard triple therapy with clarithromycin or levofloxacin has declined substantially due to increasing antimicrobial resistance. (ACG) Clinical Guideline and Maastricht Consensus recommended alternative regimens, including bismuth-containing quadruple therapy or non-bismuth concomitant therapy, as first-line therapies, particularly in areas with a high prevalence of clarithromycin resistance like Syria. Both studied regimens had equally reasonable efficacy with no serious adverse events. Further studies will help select the best first-line empirical therapy in the Syrian population for Helicobacter-Pylori Infection.

\section{Abbreviations}


PPA: per-protocol analysis

ITT: intention to treat analysis

q.i.d.: four times a day.

b.i.d.: twice a day.

q.d: Once a day.

ACG: American College of Gastroenterology

H. Pylori: Helicobacter Pylori

PPI: proton pump inhibitors

\section{Declarations}

Ethics approval and consent to participate:

It was approved by the Ethical Committee of the general assembly of Damascus hospital (Approval No:5-30-12-19). A proper consent form was collected from the patient. It was clearly stated that only clinical information will be shared in research, without mentioning any personal details at any part of the article.

Consent for publication:

We transfer, assign, or otherwise convey all copyright ownership, including any and all rights incidental thereto, exclusively to the journal, in the event that such work is published by the journal.

Availability of data and materials:

The dataset supporting the conclusions of this article is available in the [data.mendeley.com] repository, [https://data.mendeley.com/drafts/fzv77yzshx], and it will be available after 15 September 2021 to 15 September 2023

Competing interests:

The authors declare that there is no conflict of interest.

Funding:

None. No funding to declare.

Authors' contributions

all authors have read and approved the manuscript

Acknowledgements: None

\section{References}


1. Hooi JKY, Lai WY, Ng WK, Suen MMY, Underwood FE, Tanyingoh D, et al. Global Prevalence of Helicobacter pylori Infection: Systematic Review and Meta-Analysis. Gastroenterology. Elsevier; 2017;153:420-9.

2. Peterson WL. Helicobacter pylori and Peptic Ulcer Disease. New England Journal of Medicine. Massachusetts Medical Society; 1991;324:1043-8.

3. Caselli M, Alvisi V. Helicobacter pylori and peptic-ulcer disease. The Lancet. Elsevier; 2002;359:1943-4.

4. Henriksson AE, Edman AC, Held M, Wadström T. Helicobacter pylori and acute bleeding peptic ulcer. Eur J Gastroenterol Hepatol. 1995;7:769-71.

5. Ishaq S, Nunn L. Helicobacter pylori and gastric cancer: a state of the art review. Gastroenterol Hepatol Bed Bench. 2015;8:S6-14.

6. Wotherspoon AC. Gastric MALT Iymphoma and Helicobacter pylori. Yale J Biol Med. 1996;69:61-8.

7. Kim BJ, Kim HS, Jang HJ, Kim JH. Helicobacter pylori Eradication in Idiopathic Thrombocytopenic Purpura: A Meta-Analysis of Randomized Trials. Gastroenterol Res Pract [Internet]. 2018 [cited 2020 May 19];2018. Available from: https://www.ncbi.nlm.nih.gov/pmc/articles/PMC6198559/

8. Monzón H, Forné M, Esteve M, Rosinach M, Loras C, Espinós JC, et al. Helicobacter pylori infection as a cause of iron deficiency anaemia of unknown origin. World J Gastroenterol. 2013;19:4166-71.

9. Schistosomes, liver flukes and Helicobacter pylori. IARC Working Group on the Evaluation of Carcinogenic Risks to Humans. Lyon, 7-14 June 1994. IARC Monogr Eval Carcinog Risks Hum. 1994;61:1-241.

10. Helicobacter pylori Eradication to Prevent Gastric Cancer in a High-Risk Region of China: A Randomized Controlled Trial | Gastroenterology | JAMA | JAMA Network [Internet]. [cited 2020 Jul 4]. Available from: https://jamanetwork.com/journals/jama/fullarticle/197985

11. Ghotaslou R, Leylabadlo HE, AsI YM. Prevalence of antibiotic resistance in Helicobacter pylori: A recent literature review. World J Methodol. 2015;5:164-74.

12. Savoldi A, Carrara E, Graham DY, Conti M, Tacconelli E. Prevalence of Antibiotic Resistance in Helicobacter pylori: A Systematic Review and Meta-analysis in World Health Organization Regions. Gastroenterology. 2018;155:1372-1382.e17.

13. Malfertheiner P, Megraud F, O'Morain CA, Gisbert JP, Kuipers EJ, Axon AT, et al. Management of Helicobacter pylori infection-the Maastricht V/Florence Consensus Report. Gut. BMJ Publishing Group; 2017;66:6-30.

14. Cheha KM, Dib SOA, Alhalabi MM. Pilot study: Comparing efficacy of 14-day triple therapy Clarithromycin versus levofloxacin on eradication of Helicobacter pylori infection in Syrian population single-center experience. Avicenna J Med. India; 2018;8:14-7.

15. Chey WD, Leontiadis GI, Howden CW, Moss SF. ACG Clinical Guideline: Treatment of Helicobacter pylori Infection. American Journal of Gastroenterology [Internet]. 2017;112. Available from:

https://journals.Iww.com/ajg/Fulltext/2017/02000/ACG_Clinical_Guideline_Treatment_of_Helicobacter.12.aspx

16. Niv Y. Doxycycline in Eradication Therapy of Helicobacter pylori-a Systematic Review and Meta-Analysis. Digestion. 2016;93:167-73.

17. Moshkowitz M, Konikoff FM, Peled Y, Brill S, Hallak A, Tiomny E, et al. One week triple therapy with omeprazole, clarithromycin and tinidazole for Helicobacter pylori: differing efficacy in previously treated and untreated patients. Alimentary Pharmacology \& Therapeutics. 1996;10:1015-9.

18. Satoh K, Kimura K, Taniguchi Y, Kihira K, Takimoto T, Saifuku K, et al. Biopsy sites suitable for the diagnosis of Helicobacter pylori infection and the assessment of the extent of atrophic gastritis. Am J Gastroenterol. 1998;93:569-73. 
19. Lee JY, Kim N. Diagnosis of Helicobacter pylori by invasive test: histology. Ann Transl Med [Internet]. 2015 [cited 2020 May 15];3. Available from: https://www.ncbi.nlm.nih.gov/pmc/articles/PMC4293485/

20. Veijola L, Myllyluoma E, Korpela R, Rautelin H. Stool antigen tests in the diagnosis of Helicobacter pylori infection before and after eradication therapy. World J Gastroenterol. 2005;11:7340-4.

21. Federico A, Nardone G, Gravina AG, lovene MR, Miranda A, Compare D, et al. Efficacy of 5-day levofloxacincontaining concomitant therapy in eradication of Helicobacter pylori infection. Gastroenterology. 2012;143:5561.e1; quize e13-14.

22. Martínez-Mesa J, González-Chica DA, Bastos JL, Bonamigo RR, Duquia RP. Sample size: how many participants do I need in my research? Anais Brasileiros de Dermatologia. scielo; 2014;89:609-15.

23. Omair A. Sample size estimation and sampling techniques for selecting a representative sample. Journal of Health Specialties. Wolters Kluwer Medknow Publications; 2014. p. 142-7.

24. Ausvet. Epitools Epidemiological Calculators [Internet]. 2018 [cited 2021 May 2]. Available from: https://epitools.ausvet.com.au/twoproportions

25. Sakpal TV. Sample Size Estimation in Clinical Trial. Perspect Clin Res. 2010;1:67-9.

26. Eshraghian A. Epidemiology of Helicobacter pylori infection among the healthy population in Iran and countries of the Eastern Mediterranean Region: a systematic review of prevalence and risk factors. World J Gastroenterol. 2014;20:17618-25.

27. Kuo Y-T, Liou J-M, El-Omar EM, Wu J-Y, Leow AHR, Goh KL, et al. Primary antibiotic resistance in Helicobacter pylori in the Asia-Pacific region: a systematic review and meta-analysis. Lancet Gastroenterol Hepatol. 2017;2:707-15.

28. Graham DY, Lu H, Yamaoka Y. A Report Card to Grade Helicobacter pylori Therapy. Helicobacter. 2007;12:275-8.

29. Essa AS, Kramer JR, Graham DY, Treiber G. Meta-analysis: four-drug, three-antibiotic, non-bismuth-containing "concomitant therapy" versus triple therapy for Helicobacter pylori eradication [Internet]. Database of Abstracts of Reviews of Effects (DARE): Quality-assessed Reviews [Internet]. Centre for Reviews and Dissemination (UK); 2009 [cited 2020 Sep 4]. Available from: https://www.ncbi.nlm.nih.gov/books/NBK77292/

30. Yuan Y, Ford AC, Khan KJ, Gisbert JP, Forman D, Leontiadis GI, et al. Optimum duration of regimens for Helicobacter pylori eradication. Cochrane Database Syst Rev. 2013;CD008337.

31. Haddadi $\mathrm{M}-\mathrm{H}$, Negahdari B, Asadolahi R, Bazargani A. Helicobacter pylori antibiotic resistance and correlation with cagA motifs and homB gene. Postgrad Med. England; 2020;1-9.

32. Levy SB, Star L, Kupferberg ED. The misuse of antibiotics. Medical ethics (Burlington, Mass). 2004;11:5-8.

33. Schroeck JL, Ruh CA, Sellick JA, Ott MC, Mattappallil A, Mergenhagen KA. Factors associated with antibiotic misuse in outpatient treatment for upper respiratory tract infections. Antimicrobial agents and chemotherapy. 2015;59:3848-52.

34. Giono-Cerezo S, Santos-Preciado JI, Morfin-Otero MDR, Torres-Lopez FJ, Alcantar-Curiel MD. Antimicrobial resistance. Its importance and efforts to control it. Gac Med Mex. Mexico; 2020;156:171-8.

35. Kardas P. Patient compliance with antibiotic treatment for respiratory tract infections. J Antimicrob Chemother. 2002;49:897-903.

36. Grob PR. Antibiotic prescribing practices and patient compliance in the community. Scand J Infect Dis Suppl. 1992;83:7-14.

37. Eells SJ, Nguyen M, Jung J, Macias-Gil R, May L, Miller LG. Relationship between Adherence to Oral Antibiotics and Postdischarge Clinical Outcomes among Patients Hospitalized with Staphylococcus aureus Skin Infections. 
Antimicrobial Agents and Chemotherapy. American Society for Microbiology Journals; 2016;60:2941-8.

38. Nsimba SED. Problems associated with substandard and counterfeit drugs in developing countries: a review article on global implications of counterfeit drugs in the era of antiretroviral (ARVs) drugs in a free market economy. East Afr J Public Health. 2008;5:205-10.

39. Caudron J-M, Ford N, Henkens M, Macé C, Kiddle-Monroe R, Pinel J. Substandard medicines in resource-poor settings: a problem that can no longer be ignored. Trop Med Int Health. 2008;13:1062-72.

\section{Figures}

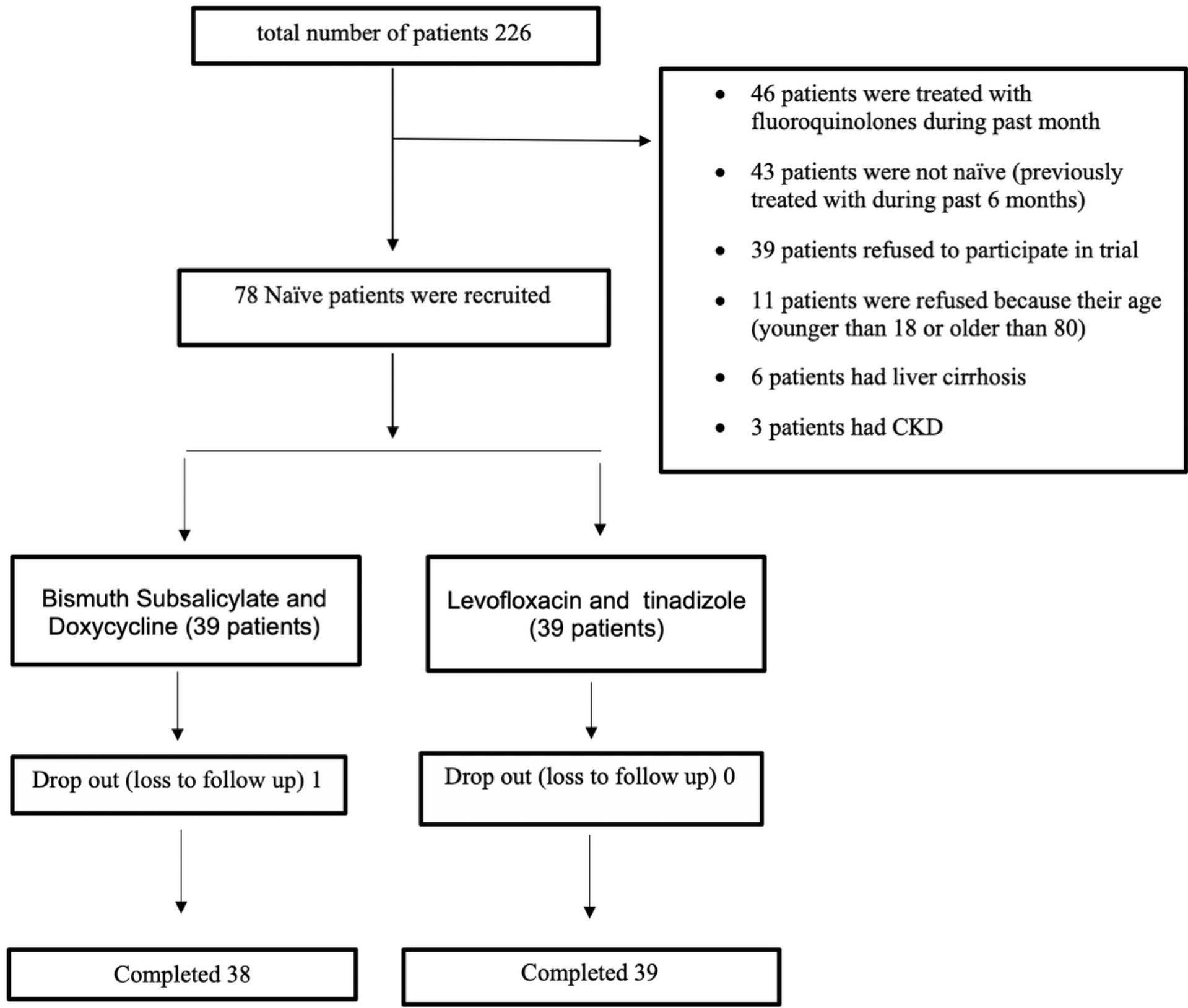

Figure 1

Patient flow chart 


\section{Supplementary Files}

This is a list of supplementary files associated with this preprint. Click to download.

- CONSORT.docx 